Research

\title{
Altering the ribosomal subunit ratio in yeast maximizes recombinant protein yield
}

\author{
Nicklas Bonander ${ }^{\dagger 1}$, Richard AJ Darby ${ }^{\dagger 1}$, Ljuban Grgic ${ }^{1}$, Nagamani Bora1, \\ Jikai Wen ${ }^{2}$, Saverio Brogna ${ }^{2}$, David R Poyner ${ }^{1}$, Michael AA O'Neill ${ }^{3}$ and \\ Roslyn M Bill*1
}

\begin{abstract}
Address: ${ }^{1}$ School of Life and Health Sciences, Aston University, Aston Triangle, Birmingham B4 7ET, UK, ${ }^{2}$ School of Biosciences, University of Birmingham, Edgbaston, Birmingham B15 2TT, UK and ${ }^{3}$ Department of Pharmacy and Pharmacology, University of Bath, Claverton Down, Bath BA2 7AY, UK

Email: Nicklas Bonander - n.bonander@aston.ac.uk; Richard AJ Darby - r.a.j.darby@aston.ac.uk; Ljuban Grgic - grgic@mrc-dunn.cam.ac.uk; Nagamani Bora - n.bora@aston.ac.uk; Jikai Wen -wxj580@bham.ac.uk; Saverio Brogna - s.brogna@bham.ac.uk;

David R Poyner - d.r.poyner@aston.ac.uk; Michael AA O'Neill - mon20@bath.ac.uk; Roslyn M Bill* - r.m.bill@aston.ac.uk

* Corresponding author †Equal contributors
\end{abstract}

Published: 29 January 2009

Microbial Cell Factories 2009, 8:10 doi:10.1 186/1475-2859-8-10
Received: 4 December 2008

Accepted: 29 January 2009

This article is available from: http://www.microbialcellfactories.com/content/8/I/10

(c) 2009 Bonander et al; licensee BioMed Central Ltd.

This is an Open Access article distributed under the terms of the Creative Commons Attribution License (http://creativecommons.org/licenses/by/2.0), which permits unrestricted use, distribution, and reproduction in any medium, provided the original work is properly cited.

\begin{abstract}
Background: The production of high yields of recombinant proteins is an enduring bottleneck in the post-genomic sciences that has yet to be addressed in a truly rational manner. Typically eukaryotic protein production experiments have relied on varying expression construct cassettes such as promoters and tags, or culture process parameters such as $\mathrm{pH}$, temperature and aeration to enhance yields. These approaches require repeated rounds of trial-and-error optimization and cannot provide a mechanistic insight into the biology of recombinant protein production. We published an early transcriptome analysis that identified genes implicated in successful membrane protein production experiments in yeast. While there has been a subsequent explosion in such analyses in a range of production organisms, no one has yet exploited the genes identified. The aim of this study was to use the results of our previous comparative transcriptome analysis to engineer improved yeast strains and thereby gain an understanding of the mechanisms involved in highyielding protein production hosts.
\end{abstract}

Results: We show that tuning BMSI transcript levels in a doxycycline-dependent manner resulted in optimized yields of functional membrane and soluble protein targets. Online flow microcalorimetry demonstrated that there had been a substantial metabolic change to cells cultured under high-yielding conditions, and in particular that high yielding cells were more metabolically efficient. Polysome profiling showed that the key molecular event contributing to this metabolically efficient, high-yielding phenotype is a perturbation of the ratio of $60 \mathrm{~S}$ to $40 \mathrm{~S}$ ribosomal subunits from approximately I:I to $2: 1$, and correspondingly of $25 \mathrm{~S}: 18 \mathrm{~S}$ ratios from $2: 1$ to $3: 1$. This result is consistent with the role of the gene product of BMSI in ribosome biogenesis.

Conclusion: This work demonstrates the power of a rational approach to recombinant protein production by using the results of transcriptome analysis to engineer improved strains, thereby revealing the underlying biological events involved. 


\section{Background}

Advances in understanding cellular function rely on improving our knowledge of protein behaviour, proteinprotein interactions, and the complex interplay of proteins with other biomolecules. Whilst structures have been solved for many individual proteins, the challenge now is to expand this specific knowledge more generically to physiologically-important, difficult-to-study eukaryotic proteins and to understand the interplay between them in complex systems. Understanding the structure and function of human proteins, and particularly membrane proteins, will not only disclose the underlying structural basis of human function but is vital in the development of new drugs in the fight against human disease [1].

As they are not naturally highly abundant, membrane proteins and many soluble eukaryotic proteins must be over-produced for the detailed studies that will reveal their biochemical, functional and structural characteristics. Therefore obtaining high yields of functional, recombinant protein remains a major bottleneck in contemporary bioscience [2]. We have shown that the root of the problem is the host organism [3], and the lack of knowledge about the intricate cellular biology within. Typically eukaryotic protein production experiments have relied on varying either promoter and fusion tag combinations in expression constructs [4] or culture process parameters such as $\mathrm{pH}$, temperature and aeration [5] to enhance yields. These approaches require repeated rounds of trial-and-error optimization and cannot provide a mechanistic insight into the biology of recombinant protein production as only external parameters are varied. This is also true of approaches which rely on the mutation of the protein target to improve its production yields [6]. The genomics revolution, however, has allowed us to take a broader but still rational approach to such optimization, which we previously adopted for recombinant membrane protein production [3] where we reported 39 host cell ( $S$. cerevisiae) genes whose expression was significantly altered when the glycerol facilitator, Fps1, was produced under high-yielding conditions $\left(20^{\circ} \mathrm{C}\right.$, pH5) compared to low-yielding standard growth conditions $\left(30^{\circ} \mathrm{C}\right.$, pH5). Although similar studies were also subsequently performed in other hosts $[7,8]$, mechanistic insight into successful recombinant protein production has remained elusive.

Building on our previous transcriptome analysis [3], we show here how we identified high-yielding strains for the well-characterized [9-11] eukaryotic glycerol facilitator, Fps1, which is a non-trivial production target for further structural study. Specifically, we characterized $s p t 3 \Delta, \operatorname{srb5} \Delta$ and $g c n 5 \Delta$ as effective production hosts for Fps1, where the yield improvement was up to a factor of 9 over the corresponding wild-type control. Improved yields of Fps1 were not explained by changes in promoter activity or FPS1 transcript number, but a post-transcriptional mechanism was suggested by the observation that each strain had elevated levels of BMS1 transcript compared to wildtype, as Bms1, the gene product of BMS1, is involved in ribosome biogenesis [12]. Subsequent overexpression of BMS1 in a doxycycline-dependent manner revealed that maximal membrane protein yield is correlated with an optimum level of BMS1 transcript for Fps1 and can be specifically tuned to maximize yields of other functional membrane (human adenosine 2A receptor) as well as soluble (green fluorescent protein) protein targets. By altering the amount of BMS1 transcript, the metabolism of high-yielding cultures changed substantially as determined by on-line flow microcalorimetry. This coincided with the ratio of $60 \mathrm{~S}$ and $40 \mathrm{~S}$ ribosomal subunits being perturbed, which we propose is the key to maximizing recombinant protein yields. This work demonstrates the power of a rational approach to recombinant protein production by finally offering an insight into the actual mechanisms involved.

\section{Results}

Three host strains deleted for genes involved in transcriptional regulation give substantially higher FpsI yields than the wild-type parent strain

43 deletion strains were screened in shake-flasks to test the effect of genes that we had previously shown to be down-regulated under high-yielding production conditions of our target protein, Fps1 [3], or that were known to be from related pathways, especially in cases where a deletion strain was non-viable. The amount of membrane-bound Fps1 from late-log phase shake-flask cultures was quantified from immunoblots relative to the wild-type yield, with all immunoblot signals being below saturation. A cut-off point twice that of the wild-type was set for selecting strains for further study resulting in three strains being analyzed in bioreactors. The three deleted genes are known to be components of the transcriptional SAGA (GCN5, SPT3) and mediator (SRB5) complexes [13]. It has been hypothesized that SAGA may have a role in the transcription of $10 \%$ of genes, most of which seem to be stress-induced and that this might reflect the need to balance inducible stress responses with the steady output of housekeeping genes [14]. In contrast, the mediator complex appears to be required for all transcriptional events and transmits regulatory signals from transcription factors to RNA polymerase II, interacting directly with the unphosphorylated carboxy-terminal domain of RNA polymerase II, forming part of the pre-initiation complex, thus stimulating transcription [15].

Figure 1 summarizes the Fps1 overproduction data from bioreactors in three $S$. cerevisiae strains and demonstrates that the spt3s strain offers a factor of 9-69 medium- 


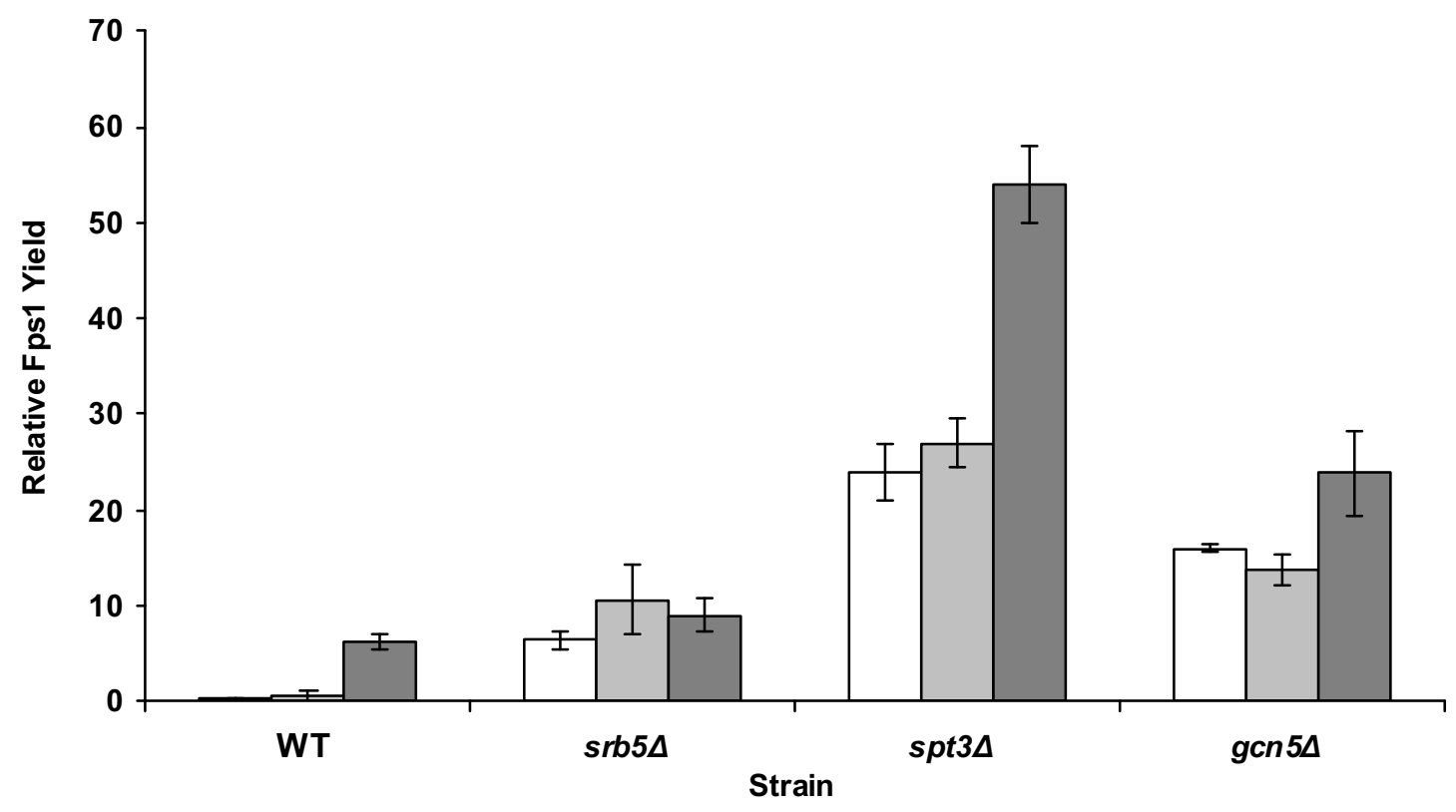

Figure I

Analysis of yields of Fps I from three deletion strains cultured in $\mathbf{2} \mathbf{L}$ bioreactors. Fps I yields are reported relative to a control sample, which previously represented our highest Fps I yield obtained [3], as described in the Methods section. The $y$-axis shows the factor improvement over the control. Maximum yields are indicated from four immunoblots from duplicate bioreactor cultures. Error bars represent the standard deviation $(n=4)$. White bars are the values for cells grown in CSM medium, pale grey for CSM medium supplemented with $10 \mu \mathrm{g} / \mathrm{mL}$ myo-inositol and dark grey bars for $2 \times$ CBS medium.

dependent increase in Fps1 yield compared with wild type, the $\operatorname{srb} 5 \Delta$ strain a factor of 1-18 increase and the $g c n 5 \Delta$ strain a factor of 4-46 increase. The spt3 $\Delta$ strain gave the highest final yield of a factor of 54 over our internal control. We also noted that the move from shake flask, where these strains were initially screened, to bioreactor had resulted in significant yield improvements for each strain relative to the wild-type: the greatest increase in yield compared to the wild-type strain in shake-flasks was only a factor of 5 for the $s p t 3 \Delta$ and $s r b 5 \Delta$ strains (data not shown). The choice of medium also had a role to play with the relationship between increased yield and medium composition being strain independent: $2 \times$ CBS was optimal in all cases (Figure 1), although CSM revealed greater improvements in the deletion strains compared to wild-type. There was no correlation between increased biomass and Fps 1 yield since the highest yield of Fps 1 was observed in early-to-mid glucose phase samples, whereas the highest biomass was always achieved in the ethanol phase. All mutant strains grew to lower cell densities than the wild type and exhibited slow-growth phenotypes. The reported auxotrophy of $s r b 5 \Delta$ for myo-inositol [16], was not a significant contributor to its phenotype under our experimental conditions with it consistently out-performing the wild type in Fps1 overproduction (Figure 1).
As the host strains were all deleted for genes involved in transcription, real time quantitative PCR (Q-PCR) was used to measure the levels of plasmid-borne FPS1 (Table 1 ) to determine whether this was correlated with the protein yields observed in Figure 1. Endogenous TPI1 levels were used as an indicator of TPI1 promoter activity, as plasmid-borne FPS1 was cloned under the control of the TPI1 promoter and it was assumed that the activities of this promoter in both contexts would be similar. Within

Table I: Fps I yield correlates with BMSI transcript number in the host cell

\begin{tabular}{|c|c|c|c|}
\hline \multirow[b]{2}{*}{ Strain } & \multicolumn{2}{|c|}{ Copies mRNA/cell } & \multirow[b]{2}{*}{ BMSI } \\
\hline & TPII & FPSI & \\
\hline wild-type & $53.6(5.0)$ & $60.1(18.2)$ & $0.1(0.0)$ \\
\hline $\operatorname{gcn} 5 \Delta$ & $15.4(3.4)^{* *}$ & $61.5(3.0)$ & $0.7(0.2)^{* *}$ \\
\hline spt3 $\triangle$ & $12.5(1.8)^{* *}$ & $64.9(26.0)$ & $0.6(0.1)^{* *}$ \\
\hline $\operatorname{srb5} 5$ & $38.2(12.5)^{*}$ & $87.4(1.5)$ & $0.7(0.2)^{* *}$ \\
\hline
\end{tabular}

Analysis of mRNA from shake-flask cultures was performed using real time quantitative PCR. The data were normalized using the reference genes $A C T I$ and PDAI and the signal was scaled to mRNA copies/cell according to a SAGE study [32], in which copies of mRNA/cell of the reference genes had previously been determined. Standard deviation in parentheses was calculated for the samples $(n=4)$. A single asterisk denotes significance at the $\mathrm{P}<0.05$ level (paired 2-tailed T-test), and a double asterisk at $P<0.01$ level. 
error we noted that RNA levels for FPS1 were comparable even though the deletion strains apparently had lower promoter activity (Table 1 ). We thus concluded that changes in the yield of Fps1 were likely to be explained by post-transcriptional events, in line with our earlier observations [3].

\section{Up-regulation of BMSI is a marker of high-yielding conditions}

Using Q-PCR, we examined changes in genes that we had previously shown to be up- or down-regulated under high-yielding production conditions [3] or that were known to be from related pathways. From this, we noted a clear relationship between Fps1 yield and a factor of 67 increase in BMS1 transcript number over wild-type in all three host strains (Table 1). In order to assess whether upregulation of BMS1 over wild-type levels is a marker of high-yielding strains, we screened three further strains, two giving wild-type- (spt8 $\Delta$, med6 $\Delta)$ and one giving improved (yTHCSRB6, where SRBG is over-expressed in a doxycycline-repressible manner) Fps1 production yields. Table 2 shows that only yTHCSRB 6 had an increase in BMS1 transcript number over wild-type, confirming that BMS1 up-regulation over wild-type levels is a marker of improved yields.

We next used a doxycycline-repressible BMS1 overexpression strain from the Open Biosystems yTHC collection (Thermo Fisher Scientific, UK) that allows gene expression to be tuned by the addition of doxycycline to the growth medium. This permitted further examination of the correlation between up-regulation of BMS1 and recombinant Fps1 yield. We found that in shake flask cultures, yield varied as doxycycline concentration (and hence BMS1 transcript number) was varied, as shown in Figure 2. Maximal Fps1 yields of a factor of 78 over wildtype were obtained at $0.5 \mu \mathrm{g} / \mathrm{mL}$ doxycycline. On culturing this strain in a bioreactor in the presence of $0.5 \mu \mathrm{g} / \mathrm{mL}$ doxycycline, the yield improvement over wild-type rose by up to a factor of 137 (data not shown). At $0.5 \mu \mathrm{g} / \mathrm{mL}$ doxycycline, the BMS1 level was 0.5 copies/cell (standard deviation $=0.1 ; \mathrm{n}=2$ ) compared with that of 0.1 copies/ cell in the wild type strain, then decreased with increasing doxycycline concentration (Figure 2).
The BMSI overexpression strain, yTHCBMSI, can be further tuned to improve the functional yield of the Gprotein coupled receptor, hA2aR, and soluble green fluorescent protein

In order to examine whether our screening strategy using Fps1 as a target, had resulted in an Fps1-specific result, we tested the human G-protein coupled receptor, A2aR in our best-performing strain. Figure 3A shows that the improvement in active $\mathrm{hA} 2 \mathrm{aR}$ as assessed by radioligand binding was small for cells cultured under conditions optimized for Fps 1 production $(0.5 \mu \mathrm{g} / \mathrm{mL}$ doxycycline $)$. On examining whether hA2aR production could be tuned further, we confirmed that maximal binding activity was obtained at a doxycycline concentration of $10 \mu \mathrm{g} / \mathrm{mL}$ (where BMS1 levels were approximately three times those in wild-type cells). Analysis of the binding curves confirmed that this was due to an increase in receptor expression (i.e. the maximum amount of ZM241385 bound) and not because of any change in the affinity of the receptor for the radioligand. Furthermore, the strain could be tuned to maximize yields of functional green fluorescent protein, doubling wild-type yields at $10 \mu \mathrm{g} / \mathrm{mL}$ doxycycline when grown in $50 \mathrm{~mL}$ shake-flask cultures (Figure 3B). These results suggested that the up-regulation of BMS1 in a target-protein-specific manner might be the key to maximizing yields for a range of proteins.

\section{On-line flow microcalorimetry data indicate different metabolic activity in high-yielding versus low-yielding strains}

We noted that high-yielding strains had lower growth rates than low yielding strains as previously observed in a wide range of cell-types, including engineered mammalian cells [17]. In order to assess whether this was accompanied by changes in metabolic activity, we used on-line flow microcalorimetry to measure the heat output of the recombinant protein-producing strains (Figure 4). The calorimetry traces in the glucose phase, where protein production peaks [3], were similar under all conditions except the maximal Fps1-yielding one (Figure 4). In the latter case, the trace mirrored the $\mathrm{OD}_{600}$-derived growth curve of yTHCBMS1 in the presence of $0.5 \mu \mathrm{g} / \mathrm{mL}$ doxycycline (Figure 4), consistent with the metabolic burden of increased recombinant protein production.

Table 2: BMSI up-regulation can be used as a marker for selecting high-yielding strains

\begin{tabular}{lll}
\hline Strain & Copies BMSI mRNA/cell & Fps I yield relative to wild-type \\
\hline wild-type & $0.1(0.1)$ & $100(27.0)$ \\
spt8 $\Delta$ & $0.2(0.0)$ & $104(28.0)$ \\
med6 & $0.2(0.1)$ & $55.6(15.0)$ \\
yTHCSRB6 & $0.8(0.3)^{* *}$ & $310(12.0)^{* *}$
\end{tabular}

Analysis of mRNA was performed as described in the legend to Table I, and of Fps I yield as described in the Methods section. Standard deviation in parentheses was calculated for the samples $(n=4)$. A double asterisk denotes significance at the $P<0.01$ level (paired 2-tailed T-test).SPT8 encodes a subunit of the SAGA complex, required for inhibition at some promoters. MED6 and SRB6 encode subunits of the mediator complex. 

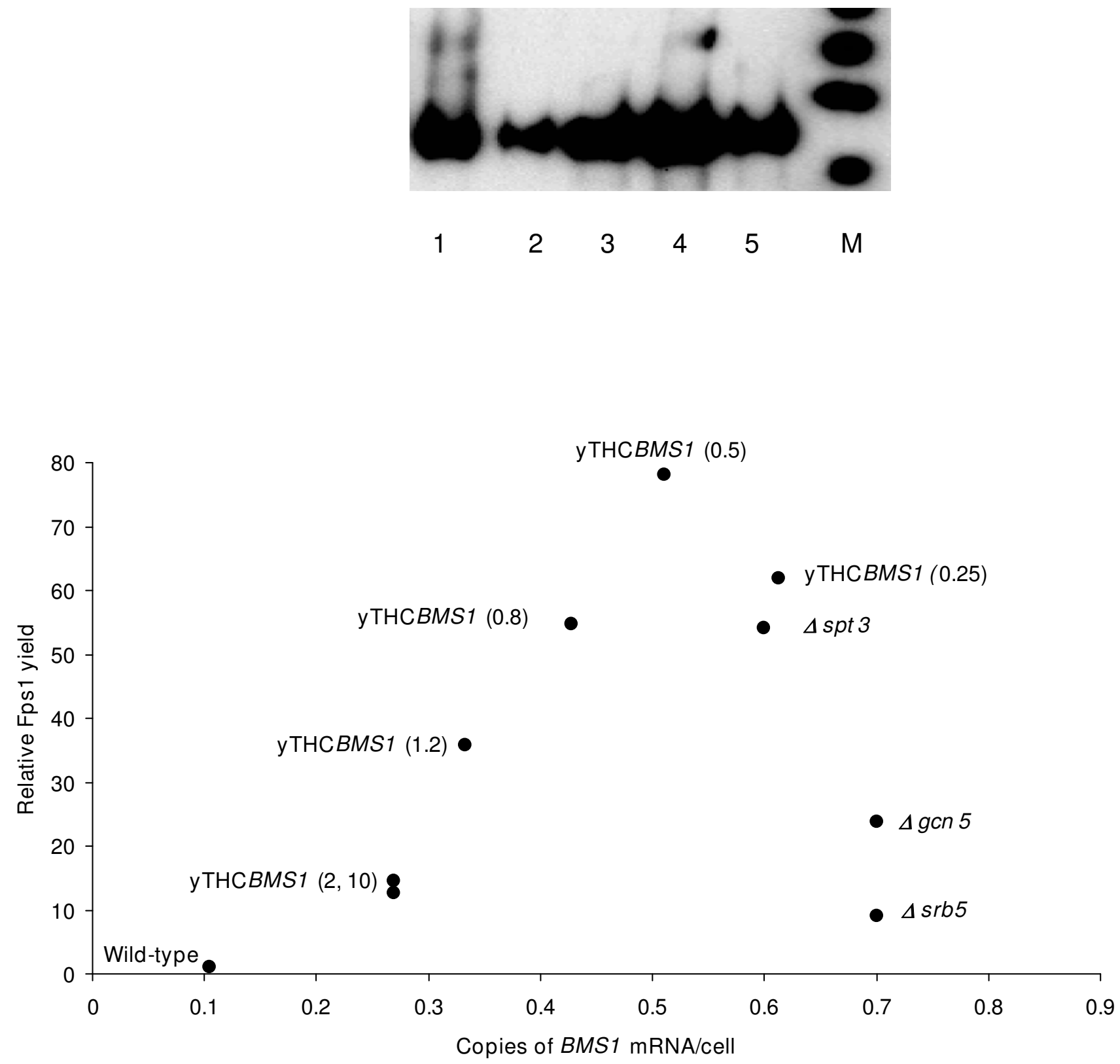

Figure 2

Maximum yields of Fps I are achieved by tuning BMSI transcript number in a doxycycline-repressible system (yTHC). FpsI yield in shake flasks is presented for the yTHCBMSI overexpression strain cultured in $2 \times$ CBS medium with varying amounts of doxycycline (the concentration in $\mu \mathrm{g} / \mathrm{mL}$ is shown in parentheses next to each point), thereby varying the copies of BMSI RNA/cell. The y-axis shows the factor improvement over the control, as for Figure I. For comparison, data for the wild-type and the three deletion strains presented in Figure I (srb5 $\Delta$, spt3 $\Delta$ and gcn5 $\Delta$ ) are also shown. Inset is a typical anti-HA-tag immunoblot showing FpsI yields for $75 \mu \mathrm{g}$ total wild-type membrane (lane I), and I5 $\mu \mathrm{g}$ total yTHCBMSI membranes extracted from shake-flask cultures grown in the presence of 0 (lane 2), 0.25 (lane 3), 0.5 (lane 4) and I0 $\mu \mathrm{g} / \mathrm{mL}$ (lane 5 ) doxycycline. The markers $(\mathrm{M})$ are $62,98,188 \mathrm{kDa}$ ascending from the bottom of the gel upwards. 
(A)

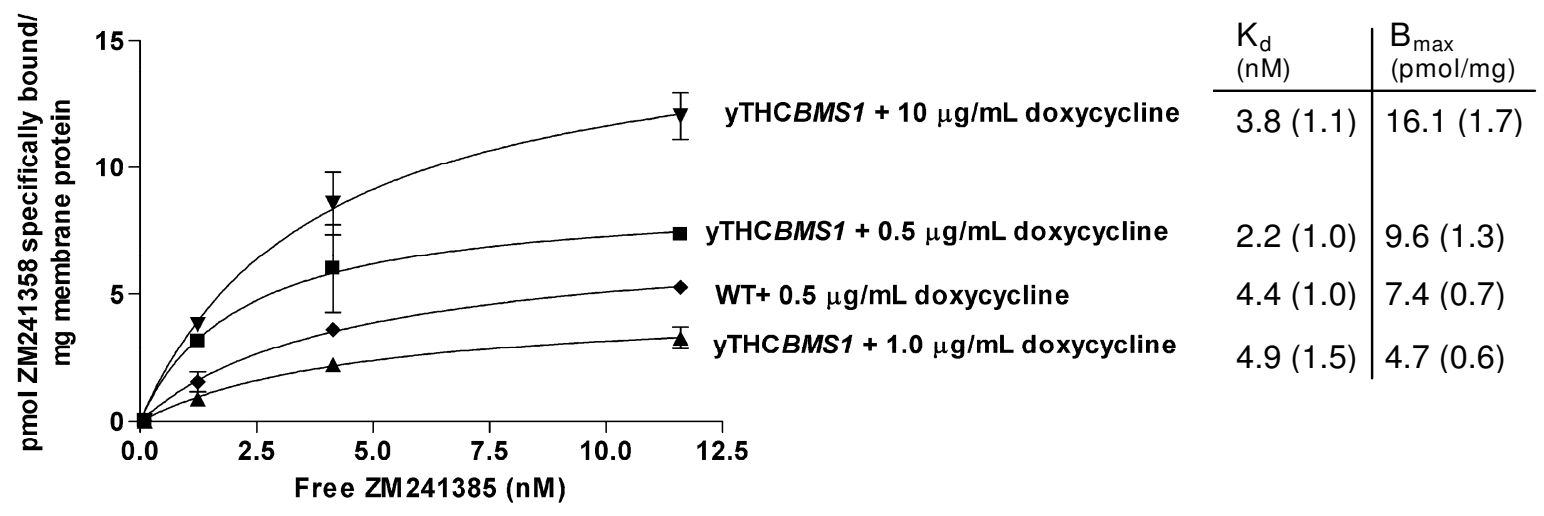

(B)

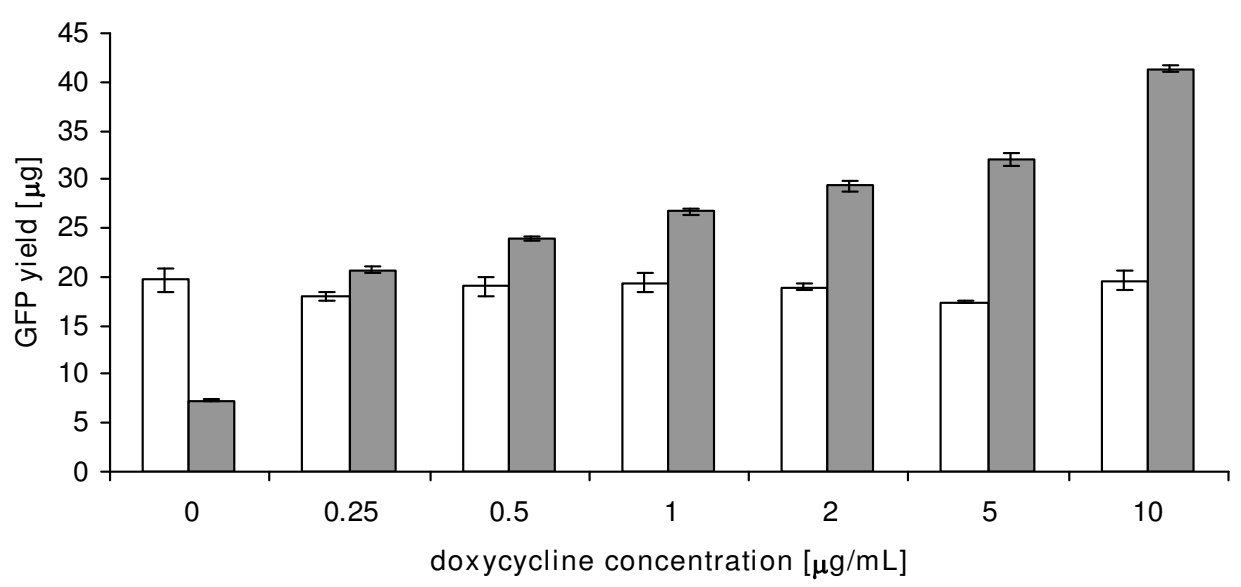

Figure 3

The yTHCBMSI strain, which produces the highest yields of Fps I, can also be used to improve the functional yield of other proteins. (A) Binding of ZM24I 385 on yeast membranes producing the G-protein coupled receptor, hA2aR is shown for duplicate determinations. Error bars represent the standard deviation $(n=2)$. Also shown are the $K_{d}(n M)$ and $B_{\max }$ (pmol receptor/mg protein) values with standard deviation given in parentheses $(n=2)$. (B) The yTHCBMSI strain (grey bars) improves the functional yield of green fluorescent protein by a factor of 2 over wild-type (white bars). Error bars represent the standard deviation $(n=3)$. Shown is the total GFP yield from a $50 \mathrm{~mL}$ culture of $\mathrm{OD}_{600}$ I.0. 


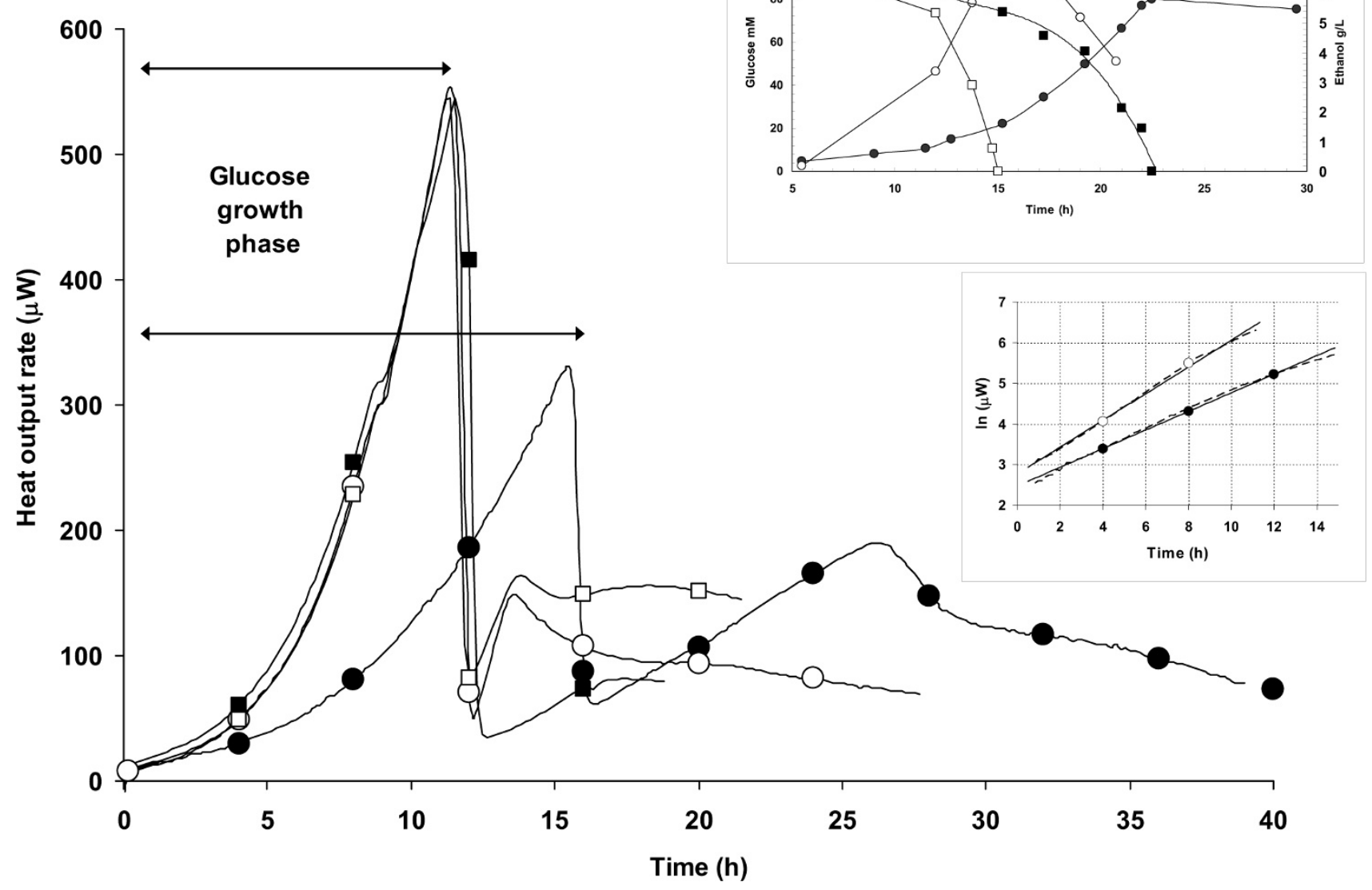

Figure 4

Calorimetric profiles for the yTHCBMSI and wild-type strains. Profiles are shown for yTHCBMSI producing Fps I in the absence (white circles) or presence (black circles) of $0.5 \mu \mathrm{g} / \mathrm{mL}$ doxycycline. Those for the wild-type in the absence (white squares) or presence (black squares) of $0.5 \mu \mathrm{g} / \mathrm{mL}$ doxycycline overlay the former trace. The top inset panel shows the glucose (squares) and ethanol (circles) data for the yTHCBMSI strain producing FpsI in the absence (white symbols) or presence (black symbols) of $0.5 \mu \mathrm{g} / \mathrm{mL}$ doxycycline. The lower inset shows the natural log plot of the glucose phase data for the YTHCBMSI strain, showing the linear fit used to calculate rate constants of $0.32 \mathrm{~h}^{-1}$ and $0.21 \mathrm{~h}^{-1}$ in the absence (white circles) or presence (black circles) of $0.5 \mu \mathrm{g} / \mathrm{mL}$ doxycycline, respectively.

As expected, the heat outputs in all but the maximal Fps1yielding conditions were indistinguishable. A natural log plot of the glucose growth phases for the low-yielding strains had highly similar pseudo-first order rate constants of $0.39 \mathrm{~h}^{-1}, 0.37 \mathrm{~h}^{-1}$ and $0.32 \mathrm{~h}^{-1}$, for the wild-type in the absence or presence of doxycycline, and yTHCBMS1 in its absence, respectively, yielding a mean growth rate of 0.36 $\mathrm{h}^{-1}$ (where the standard deviation is 0.04). This is in excellent agreement with the mean growth rate of $0.34 \mathrm{~h}^{-1} \mathrm{cal}-$ culated from $\mathrm{OD}_{600}$ values and dry weights (Figure 4, lower insert) and is in line with typical growth rates for glucose-grown S. cerevisiae in bioreactors [18]. In contrast the mean growth rate for the maximal Fps1-yielding conditions (yTHCBMS1 in the presence of $0.5 \mu \mathrm{g} / \mathrm{mL}$ doxycy- cline) was calculated to be $0.21 \mathrm{~h}^{-1}$ from triplicate determinations (standard deviation is 0.02), indistinguishable from $0.19 \mathrm{~h}^{-1}$ calculated from $\mathrm{OD}_{600}$ values and dry weights (Figure 4 ). This is $58 \%$ of the mean growth rate for the low-yielding strains and is clearly reflected in the differing peak areas of the glucose growth phases (Figure 4): the corresponding heat yields for yTHCBMS1 in the presence and absence of $0.5 \mu \mathrm{g} / \mathrm{mL}$ were $5.4 \mathrm{~kJ} / \mathrm{g}$ and $6.5 \mathrm{~kJ} / \mathrm{g}$, respectively. This suggested a substantially different metabolism in high-yielding compared to low-yielding cultures, consistent with the different ethanol profiles (Figure 4, upper insert). 


\section{Maximum protein yield is accompanied by an altered 60S:40S subunit ratio in the host cell}

We wished to identify a molecular event that might explain the apparently changed metabolism of high-yielding cells. As Bms1 has previously been reported to have a role in ribosome biogenesis [12], we therefore examined the polysome profile for yTHCBMS1 producing recombinant Fps1 in the presence and absence of $0.5 \mu \mathrm{g} / \mathrm{mL}$ doxycycline, the former condition giving maximal Fps1 yield compared to wild-type under the same conditions. As we had seen with the microcalorimetry traces, Figure $5 \mathrm{~A}$ shows that the polysome profiles were similar under all conditions except the maximal Fps1-yielding one (lower right-hand panel) where elevated levels of free 60S subunits were clearly apparent. There was also an increased proportion of free 60S subunit for yTHCBMS1 in the absence of doxycycline (upper right-hand panel). These observations were supported when the ribosomes were disassociated with EDTA (Figure 5B): in the BMS1 overexpression strain, the relative proportion of 605 subunit was shown to be increased compared to wild-type in both the absence and presence of doxycycline. In relation to this, in the absence of doxycycline the Fps1 yield is increased by a factor of 10 over wild-type, while at $0.5 \mu \mathrm{g} /$ $\mathrm{mL}$ it is increased by a factor of 78 , suggesting that a change in the proportions of 605 and 405 subunits may result in an increased protein yield. Despite differences in the absolute peak heights, the ratio of 605 to $40 \mathrm{~S}$ was similar in all traces in Figure 5B except the maximal Fps1yielding one (lower right-hand panel). In this latter condition, the relative amount of $40 \mathrm{~S}$ was lower than in all other conditions leading to a 2:1 ratio of 605 to $40 \mathrm{~S}$ in comparison with a ratio of approximately $1: 1$ for all other conditions tested. Profiles for yTHCBMS1 cultured in 0, $0.25,0.5,1.0,4.0$ and $10.0 \mu \mathrm{g} / \mathrm{mL}$ doxycycline, showed that the relative proportion of $40 \mathrm{~S}$ subunit decreased as expected [12] to below our detection limit with increasing doxycycline concentration, whilst the elevated level of 605 compared to wild-type remained essentially constant (data not shown). In agreement with this, 25S:18S ratios were 2:1 in the absence of doxycycline, in agreement with typical values for wild-type S. cerevisiae [19], but increased to $3: 1,5: 1$ and $7: 1$ at 0.5 .2 .0 and $5.0 \mu \mathrm{g} / \mathrm{mL}$ doxycycline respectively.

\section{Discussion}

A recent analysis of membrane protein production in $E$. coli [7] reported that increases in levels of chaperones and proteases were associated with increased membrane protein production and it was speculated that low yields were due to limited Sec translocon capacity. Our previous transcript analysis identified up-regulation of SEC62 in high yielding protein production. Sec62 is an essential subunit of the Sec63 complex (Sec63, Sec62, Sec66 and Sec72) and with the Sec61 complex, Kar2/BiP and Lhs1 forms a channel competent for SRP-dependent and post-translational SRP-independent protein targeting and import into the ER [20]. We found a SEC63 over-expression strain from the Open Biosystems yTHC $S$. cerevisiae collection did not give improved recombinant protein yields. Additionally, we found that SRP102, which encodes the signal recognition particle receptor $\beta$ subunit, was down-regulated in high-yielding experiments and again that a $\operatorname{srp} 102 \Delta$ strain gave only wild-type yields of Fps1. Whilst this does not preclude the eukaryotic secretory pathway from having a limiting effect in S. cerevisiae translational efficiency it does highlight clear differences between prokaryotic and eukaryotic cells.

We found instead that a common theme in our highyielding strains was the up-regulation of BMS1 by a factor of 6-7 over wild-type (Table 1) suggesting the importance of ribosome biogenesis in maximizing production yield. Bms1 is an essential nucleolar protein that is evolutionarily conserved throughout the eukaryotic kingdom and has been suggested to have a regulatory role in the biogenesis of the 40 S subunit [12] as well as being a GTP-binding protein [21]. Further experiments have led to the current model of Bms1 binding to the product of a second essential gene, Rcl1, in a GTP-dependent manner and shuttling Rcl1 to pre-ribosomes via its affinity for U3 snoRNA [22]. Our unpublished data suggest that over-expression of RCL1 in a doxycycline-dependent manner does not lead to improved yields, although this could be a result of Bms 1 being limiting in a Bms1/Rcl1 complex. Nonetheless, recombinant protein translation was clearly enhanced by the overexpression of BMS1 alone (Figure 2).

Interestingly, it has previously been reported that mice in which deletion of both genes for ribosomal protein S6 led specifically to a lack of $40 S$ synthesis, but normal 60S synthesis, in the liver survived for several weeks. Their livers could respond to fasting and re-feeding cycles, in which the mass of the liver nearly doubles. However, whereas partial hepatectomy in normal animals leads to rapid regrowth and cell division, the livers of mice defective in the production of $40 \mathrm{~S}$ ribosomal subunits did not re-grow and showed no signs of cell division [23]. These results imply that a lack of $40 \mathrm{~S}$ ribosome biogenesis can induce a checkpoint control that prevents cell cycle progression. This is entirely consistent with our observed slowing of growth that accompanied high-yielding protein production which has been widely reported by others as a feature of successful protein production hosts [24] and measured by on-line gas analysis [25]. Our own data support an interpretation that the yTHCBMS1 strain at $0.5 \mu \mathrm{g} / \mathrm{mL}$ doxycycline (high yielding conditions) has low fermentative activity, since it produces $16 \%$ less ethanol than the wild-type strain under the same conditions. Dry weights in the high yielding condition were also $6.5 \%$ lower than 

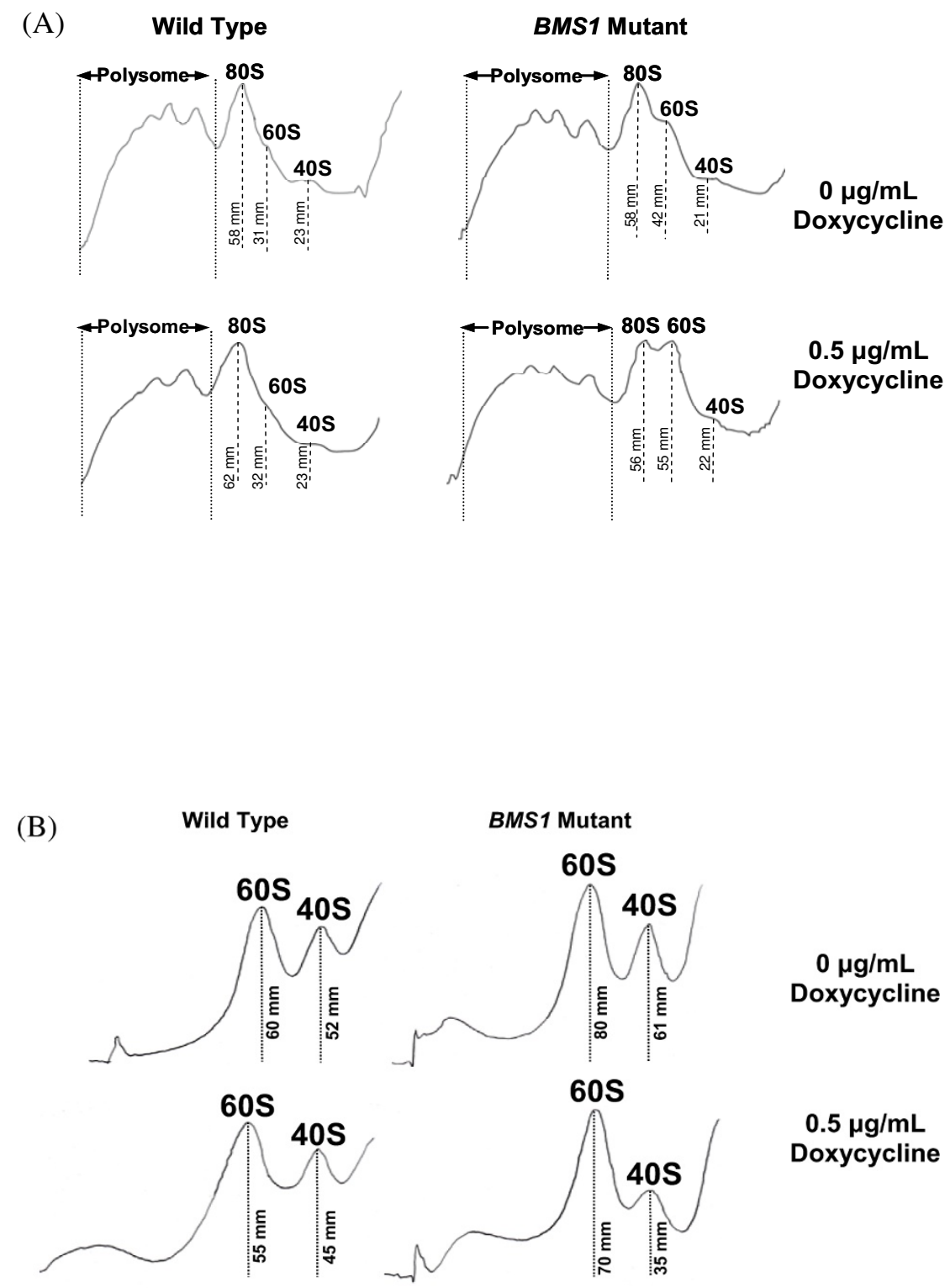

\begin{tabular}{l|ll||l} 
Change in peak heights (\%) between culture conditions & $\mathbf{4 0 S}$ & $\mathbf{6 0 S}$ & $\begin{array}{l}\text { Change in } \\
\text { 60S:40S }\end{array}$ \\
\hline WT to WT + doxycycline & -13.5 & -8.3 & No change \\
WT to yTHCBMS1 & +17.3 & +33.3 & No change \\
WT to yTHCBMS1 + doxycycline & -32.7 & +16.7 & 1.2 to 2.0 \\
yTHCBMS1 to yTHCBMS1 + doxycycline & -42.6 & -12.5 & 1.3 to 2.0
\end{tabular}

\section{Figure 5}

Polysome profiles for the yTHCBMSI and wild-type strains. (A) Polysome $\mathrm{OD}_{254}$ Profiles for yeast strains producing Fps I in the absence (upper panels) or presence (lower panels) of $0.5 \mu \mathrm{g} / \mathrm{mL}$ doxycycline. Polysome peaks containing 2 , 3 and 4 ribosomes are visible. (B) Ribosome disassociation profiles at $\mathrm{OD}_{254}$ for $50 \mathrm{mM}$ EDTA-treated samples of wild-type and yTHCBMSI strains producing FpsI in the absence and presence of $0.5 \mu \mathrm{g} / \mathrm{mL}$ doxycycline (upper and lower panels respectively). Changes in peak heights and ratios of $60 \mathrm{~S}$ and $40 \mathrm{~S}$ subunits for all four conditions are tabulated. 
in poor yielding conditions over a full growth curve (122 h) in agreement with the observation that $1 \mathrm{~g}$ ethanol leads to $0.25 \mathrm{~g}$ dry weight in a typical yeast fermentation [26], and so $16 \%$ less ethanol should lead to $4 \%$ less dry weight. Furthermore the yTHCBMS1 strain had a lower average exponential phase RQ in the presence of $0.5 \mu \mathrm{g} /$ $\mathrm{mL}$ doxycycline $(\mathrm{RQ}=3.6)$ than in its absence $(\mathrm{RQ}=4.1$; in excellent agreement with literature values for wild-type strains grown on glucose [18]).

These observations are supported by our on-line flow microcalorimetry data. Kemp and co-workers were amongst the first to apply this technique to recombinant systems [17] and recently Gill and colleagues reported 'thermal profiling' as a method for on-line analysis of the growth of $E$. coli cultures expressing cyclohexanone monooxygenase under the control of an L-arabinose promoter in a multi-well format [27]. In the study presented here, we took the next step by using thermal profiles to rationalize the underlying mechanisms at work in our high-yielding cultures. The reduction in heat yield we observed suggests that high-yielding cells have a more efficient metabolism than low-yielding cells. As ribosome biogenesis is a major consumer of cellular energy resources [28] and its regulation is intimately linked to cell size, which in turn affects cell growth [29] as well as influencing other features such as the way that cells respond to stress [30], we hypothesized that the mechanism underlying this changed metabolism could be due to changes in ribosomal composition. The polysome profile for the high-yielding strain in which BMS1 is overexpressed in the presence of optimal levels of doxycycline for maximal Fps1 yield (at $0.5 \mu \mathrm{g} / \mathrm{mL}$, Figure $5 \mathrm{~A}$ ) showed elevated levels of $60 \mathrm{~S}$ subunits without any significant decrease in the levels of $80 \mathrm{~S}$ or polysome. On further probing this by disassociating the ribosomes with EDTA, it could be seen that the ratio of $60 \mathrm{~S}$ to $40 \mathrm{~S}$ had been perturbed from wild-type levels of close to $1: 1$ to $2: 1$. This might suggest a previously unreported role (direct or indirect) for Bms1 in 605 biogenesis and also the possibility of an underlying mechanism in which binding and release of the 605 ribosomal subunit might be rate-limiting. We speculate that perturbing the ratio of the ribosomal subunits is key to maximizing recombinant protein yields by making protein production a more efficient cellular process. This might be influenced by an altered dynamic equilibrium between the transcript: $40 \mathrm{~S}$ complex and the $60 \mathrm{~S}$ subunit which is available in greater amounts in the highyielding strain. Of course it is also possible that some other component is affected by the perturbed 60S:40S ratio; both possibilities are the subject of our ongoing investigations.

\section{Conclusion}

Our data show that recombinant protein production can be rationalized, guided by the results of transcriptome analysis of the host strain response. We specifically identify $B M S 1$ as a gene whose expression can be tuned to facilitate high yielding protein production experiments. Under these conditions, there is a perturbation in the ratio of ribosomal subunits and the metabolism of the host cell is more efficient with respect to protein production.

\section{Methods}

\section{Vectors}

The FPS1 gene was tagged at its 3' end replacing the carboxy-terminal threonine residue with a sequence encoding three HA epitopes to permit immunodetection: SGRIFYPYDVPDYAGYPYDVPDYAGYPYDVP-

DYAAQCGR. The HA sequences are underlined. The construct was expressed from the TPI promoter in the 2 $\mu \mathrm{pYX} 212$ and pYX222 vectors (Novagen; now discontinued) which contain the URA3 and HIS3 selection markers respectively. The gene was cloned into the Bam $\mathrm{H} 1$ and HindIII sites and the vectors transformed into S. cerevisiae using the lithium acetate method. The GFP (GenBank U62636) and hA2aR [31] genes were amplified by PCR and cloned into the HindIII and XmaI sites and the HindIII and SalI sites of pYX212 and pYX222, respectively. The GFP gene was cloned with an $\alpha$-secretion factor to facilitate secretion into the culture medium.

\section{Yeast strains and culturing conditions}

S. cerevisiae BY4741 is the parental strain for the deletion mutants spt3 $\Delta, s r b 5 \Delta$ and $g c n 5 \Delta$ from the EUROSCARF collection http://web.uni-frankfurt.de/fb15/mikro/euro scarf and the yTHCBMS1 strain (Open Biosystems) used in this study, and as such provided the wild-type control. Yeast cells were cultured in $2.5 \mathrm{~L}$ bioreactors containing 2 L of either CSM \pm myo-inositol or $2 \times$ CBS. CSM was composed of $1.7 \mathrm{~g} / \mathrm{L}$ yeast nitrogen base (YNB) without amino acids, $5 \mathrm{~g} / \mathrm{L}$ ammonium sulphate supplemented with $2 \%$ glucose $\pm 10 \mu \mathrm{g} / \mathrm{mL}$ additional myo-inositol, $2 \times$ DO solution minus histidine or minus uracil (Clontech Yeast Protocols Handbook Version PR13103) and 10 mM MES pH 6. $2 \times$ CBS was composed of $10 \mathrm{~g} / \mathrm{L}$ ammonium sulphate, $6 \mathrm{~g} / \mathrm{L}$ potassium dihydrogen phosphate, $1 \mathrm{~g} / \mathrm{L}$ magnesium sulphate supplemented with $2 \%$ glucose, $2 \mathrm{~mL} / \mathrm{L}$ each of trace element solution and vitamin stock solution (recipes shown below) and $2 \times$ DO solution minus histidine or minus uracil. The $\mathrm{pH}$ was adjusted to, and maintained at, 6 via the online addition of $0.5 \mathrm{M} \mathrm{NaOH}$. The agitation, aeration and temperature of the cultures were maintained at $700 \mathrm{rpm}, 1 \mathrm{~L}$ per min and $30^{\circ} \mathrm{C}$ respectively. $1 \mathrm{~L}$ trace element solution was composed of the following: $15 \mathrm{~g}$ EDTA, $4.5 \mathrm{~g} \mathrm{ZnSO}{ }_{4} \cdot 7 \mathrm{H}_{2} 0$, $1 \mathrm{~g} \mathrm{MnCl}_{2} \cdot 4 \mathrm{H}_{2} \mathrm{O}, 0.3 \mathrm{~g}$ $\mathrm{CoCl}_{2} \cdot 6 \mathrm{H}_{2} \mathrm{O}, \quad 0.3 \mathrm{~g} \quad \mathrm{CuSO}_{4} \cdot 5 \mathrm{H}_{2} \mathrm{O}, \quad 0.4 \mathrm{~g}$ $\mathrm{Na}_{2} \mathrm{MoO}_{4} \cdot 2 \mathrm{H}_{2} \mathrm{O}, 4.5 \mathrm{~g} \mathrm{CaCl}_{2} \cdot 2 \mathrm{H}_{2} \mathrm{O}, 3 \mathrm{~g} \mathrm{FeSO}_{4} \cdot 7 \mathrm{H}_{2} \mathrm{O}, 1$ 
$\mathrm{g} \mathrm{H}_{3} \mathrm{BO}_{3}$ and $0.1 \mathrm{~g} \mathrm{KI}$. The $\mathrm{pH}$ was maintained at 6.0 with $1 \mathrm{M} \mathrm{NaOH}$ throughout the addition and finally adjusted to $\mathrm{pH} 4$ with $1 \mathrm{M} \mathrm{HCl}$ prior to autoclave sterilisation and storage at $4^{\circ} \mathrm{C}$. $1 \mathrm{~L}$ vitamin solution was composed of the following: $0.05 \mathrm{~g}$ D-biotin, $1 \mathrm{~g} \mathrm{Ca} \mathrm{D} \mathrm{(+)} \mathrm{panthothenate,} 1$ $\mathrm{g}$ nicotinic acid, $25 \mathrm{~g}$ myo-inositol, $1 \mathrm{~g}$ thiamine hydrochloride, $1 \mathrm{~g}$ pyridoxol hydrochloride and $0.2 \mathrm{~g}$ D-amino benzoic acid. $\mathrm{pH}$ maintained at 6.5 with $1 \mathrm{M} \mathrm{HCl}$. The vitamin solution was filter sterilized and stored as $20 \mathrm{~mL}$ aliquots at $4{ }^{\circ} \mathrm{C}$. Plasmid retention was verified by the plating of the cells onto CSM + inositol agar in the absence of histidine or uracil and incubation at $30^{\circ} \mathrm{C}$ for 4 days. To initiate each experiment, $50 \mathrm{~mL}$ of a given medium were inoculated with fresh yeast cells in a baffled shake flask and cultured for up to $72 \mathrm{~h}$ in a shaking incubator at $30^{\circ} \mathrm{C}, 220 \mathrm{rpm}$. This pre-culture was subsequently used to inoculate $200 \mathrm{~mL}$ of the same medium in a baffled shake flask and cultured under the conditions outlined above to an $\mathrm{OD}_{600}$ of 1 . This was then used to inoculate the bioreactors to initial $\mathrm{OD}_{600}=0.05$. For the production of hA2aR, the strains BY4714 and yTHCBMS1 were transformed with hA2aR vectors and cultured in 1.75 L $2 \times$ CBS supplemented with $10 \mathrm{mM}$ theophylline and $0.5,1.0$ or $10.0 \mu \mathrm{g} / \mathrm{mL}$ doxycycline. The cells were harvested by centrifugation once the glucose concentration of the cultures was in the range $5-10 \mathrm{mM}$.

\section{Sampling, extracellular substrate determination and membrane preparation}

Samples were withdrawn at various points in both the glucose and ethanol phases. 15 - $100 \mathrm{~mL}$ culture were centrifuged at $5000 \times \mathrm{g}, 4^{\circ} \mathrm{C}$ for $5 \mathrm{~min}$. $0.5 \mathrm{~mL}$ of the supernatant was stored at $-20^{\circ} \mathrm{C}$ for glucose and ethanol analyses. The cell pellets were frozen in liquid nitrogen and stored at $-80^{\circ} \mathrm{C}$ for subsequent membrane preparation. Ethanol analysis (10176290035, R-Biopharm, Germany) was performed according to the manufacturer's instructions. Glucose concentrations were calculated with an Accu-Chek Active glucose analyzer (Roche Diagnostics, UK). Cell pellets were fractionated with glass beads $(1: 1$ ratio) in $2 \mathrm{~mL}$ cell breaking buffer $(50 \mathrm{mM}$ potassium phosphate $\mathrm{pH} 7.4,100 \mathrm{mM} \mathrm{NaCl}, 0.5 \mathrm{mM}$ EDTA, 5\% glycerol, $4 \mathrm{mM}$ PMSF). The cells were agitated in a Fast Prep (Thermo Fisher Scientific, UK) at speed 6.5, employing $6 \times 40 \mathrm{~s}$ pulses with $2 \mathrm{~min}$ incubations on ice between pulses. The samples were clarified at $10,000 \times \mathrm{g}, 4^{\circ} \mathrm{C}$ for $30 \mathrm{~min}$ and the total membrane pellet recovered from the supernatant at $100,000 \times \mathrm{g}, 4^{\circ} \mathrm{C}$ for $60 \mathrm{~min}$. Total membranes were re-suspended in $50 \mu \mathrm{L}$ of Buffer A $(20 \mathrm{mM}$ Hepes $\mathrm{pH} 8,50 \mathrm{mM} \mathrm{NaCl}, 10 \%$ glycerol $\mathrm{w} / \mathrm{v}$ ) and the total protein concentration determined using a Bio-Rad (Hemel Hempstead, UK) Bradford-based assay with bovine serum albumin as standard. Dry-weight determinations were performed by collecting two samples of $5 \mathrm{~mL}$ by centrifugation for $5 \mathrm{~min}$ at $5,000 \mathrm{~g}$. The cells were washed once in $5 \mathrm{~mL}$ water, dried for $24 \mathrm{~h}$ at $110^{\circ} \mathrm{C}$, and stored in a desiccator for $24 \mathrm{~h}$ before being weighed. Typical dry weights were $2.1 \mathrm{~g} / \mathrm{L}$ for low-yielding conditions and $2.0 \mathrm{~g} / \mathrm{L}$ for high yielding conditions after completion of the glucose growth phase.

\section{Immunoblotting and yield analysis}

$30-75 \mu$ g of total membranes were loaded per lane on an $8 \%$ polyacrylamide gel and separated by SDS-PAGE at $150 \mathrm{~V}$ for $1.25 \mathrm{~h}$. Proteins were subsequently transferred to a nitrocellulose membrane (ProTran; Geneflow, UK) at $100 \mathrm{~V}$ for $1 \mathrm{~h}$. The membrane was blocked with phosphate-buffered saline (PBS) containing 5\% milk overnight at $4{ }^{\circ} \mathrm{C}$ before incubating with mouse monoclonal anti-HA (clone 12CA5; Roche Diagnostics, UK) at a 1:5,000 dilution in PBS/5\% milk for $1 \mathrm{~h}$ at room temperature with gentle agitation. The membrane was subsequently washed twice with PBS/0.2\% Tween 20 for 5 min before incubating with goat anti-mouse horseradish peroxidase-conjugated secondary monoclonal antibody (Sigma-Aldrich, UK) at a 1:5,000 dilution in PBS/5\% milk for $1 \mathrm{~h}$ at room temperature with gentle agitation. The membrane was washed as above and developed using an enhanced chemiluminesence detection kit (Geneflow, UK) following the manufacturer's instructions and visualized with a Chemidoc (UVItech, UK). The signal from each lane was quantified using either UVIband or the ImageGauge programme and was expressed as the factor improvement over our internal control (which is the previously-reported reference yield of Fps 1 per $\mu \mathrm{g}$ of total membrane [3]) and was corrected for the amount of total membranes loaded per lane.

\section{Radioligand binding assay}

Harvested cells were re-suspended in $30 \mathrm{~mL}$ breaking buffer and disrupted at 30,000 psi for 10 min using an Avestin C3. The samples were clarified by centrifugation at $10,000 \times \mathrm{g}, 4^{\circ} \mathrm{C}$ for $30 \mathrm{~min}$ and total membranes recovered from the supernatant at $100,000 \times \mathrm{g}, 4^{\circ} \mathrm{C}$ for $60 \mathrm{~min}$. Total membranes were re-suspended in $2.5 \mathrm{~mL}$ Buffer A, the protein concentration determined using a NanoDrop 1000 (Thermo Fisher Scientific, UK) and $0.5 \mathrm{~mL}$ aliquots stored at $-80^{\circ} \mathrm{C}$. Membrane bound hA2aR was then determined using a radioligand binding assay based on the protocol of Fraser [31]. Membranes at $0.5 \mathrm{mg} / \mathrm{ml}$ with 0.1 $\mathrm{U}$ of adenosine deaminase were incubated with varying concentrations of ${ }^{3} \mathrm{H} \mathrm{ZM} 241385$ for $60 \mathrm{~min}$ at $30^{\circ} \mathrm{C}$ and non-specific binding was defined by including $1 \mu \mathrm{M}$ ZM241385 in the incubations. Assays were terminated by centrifugation at $14,000 \mathrm{rpm}$ in a bench-top centrifuge for $5 \mathrm{~min}$. The supernatant was discarded, the pellets washed superficially with water and solublilized with Soluene, which was added to scintillation fluid and then counted to determine bound radioactivity. Binding was analyzed 
using PRISM Graphpad v 4.0 to determine $\mathrm{K}_{\mathrm{d}}$ and binding capacity.

\section{GFP fluorescence measurements}

$50 \mathrm{~mL}$ of $2 \times$ CBS medium were inoculated with individual yeast colonies transformed with the GFP vector and cultured for up to $48 \mathrm{~h}$ in the presence or absence of various doxycycline concentrations at $220 \mathrm{rpm}$ and $30^{\circ} \mathrm{C}$. These cultures were used to inoculate fresh $50 \mathrm{~mL} 2 \times \mathrm{CBS}$ medium to a final $\mathrm{OD}_{600}$ of 0.1 and were cultured as above for $16-20$ h. $1 \mathrm{~mL}$ samples were withdrawn and the cells pelletted at $5,000 \times \mathrm{g}, 4^{\circ} \mathrm{C}$ for $5 \mathrm{~min}$ and the supernatant collected. $200 \mu \mathrm{L}$ supernatant were loaded in triplicate in a black Nunc MaxiSorp 96-well plate and the fluorescence recorded on a SpectraMax Gemini XS plate reader (Molecular Devices, Wokingham, UK) with excitation and emission wavelengths of $390 \mathrm{~nm}$ and $510 \mathrm{~nm}$ respectively, and a cut-off of $495 \mathrm{~nm}$. Doxycycline fluorescence accounted for less than $5 \%$ of the signal up to concentrations of $10 \mu \mathrm{g} / \mathrm{mL}$.

\section{RNA preparation and real time quantitative $P C R$}

Yeast cells $(60 \mathrm{~mL})$ from two biological replicates and two technical replicates were harvested and frozen in liquid nitrogen. Total RNA was then prepared using the RNeasy kit from Qiagen with on-column DNAse treatment, following the manufacturer's instructions. Analysis of mRNA was performed using real time quantitative PCR (Q-PCR). $1.1 \mu \mathrm{g}$ RNA was used in the cDNA reaction using the iScript cDNA Synthesis Kit (Bio-Rad, UK). Each sample was amplified using up to 30 cycles $\left(20 \mathrm{~s} 94^{\circ} \mathrm{C} ; 20 \mathrm{~s} 60^{\circ} \mathrm{C}\right.$; $20 \mathrm{~s} 72^{\circ} \mathrm{C}$ ) in a Bio-Rad iCycler iQ, and the data were analyzed using iCycler IQ version 3.0. The data were normalized using the reference genes PDA1 and ACT1 and the signal was scaled to mRNA copies/cell according to a SAGE study [32] in which copies of mRNA/cell of all the reference genes had previously been determined.

\section{On-line flow microcalorimetry}

Flow microcalorimetric data were collected for bioreactorgrown cultures as detailed above, in the absence or presence of $0.5 \mu \mathrm{g} / \mathrm{mL}$ doxycycline using a Thermal Activity Monitor 2277 (Thermometric AB, Sweden) with a flow vessel working volume of $0.6 \mathrm{~cm}^{3}$. The system was sterilized by successively pumping through solutions of sterile deionized water, $70 \%$ ethanol $(\mathrm{v} / \mathrm{v})$, sodium hydroxide $(0.5 \mathrm{M})$ and finally sterile deionized water. The thermostatic water bath was maintained at $30^{\circ} \mathrm{C}$, a sampling interval of $600 \mathrm{~s}$ was chosen in the Digitam v4.1 software and the pumping rate was set at $48 \mathrm{~mL} / \mathrm{h}$ (Watson Marlow 400-403 u/VM2, $30 \mathrm{rpm}$ ). The calorimeter was calibrated at the same temperature, flow rate and amplifier setting $(1000 \mu \mathrm{W})$ to be used during experimental data collection in order to establish a steady baseline deflection. Electrical calibration was done in the culture medium. Once the baseline was established, the inlet and outlet tubes were placed in the bioreactor in the presence of $70 \%$ ethanol prior to inoculation in order to maintain sterility. Powertime data were imported into Microcal Origin 7.0 where all subsequent data analysis was performed. Pseudo $1^{\text {st }}$ order rate constants were extracted from the calorimetric data using the equation below [33], for a flowing system that conforms to $1^{\text {st }}$ order kinetics.

$$
\Phi=-F C H\left(1-e^{-k_{1} \tau}\right) e^{-k_{1} t}
$$

where $\Phi$ is the calorimetric output $\left(\mathrm{Js}^{-1}\right)$; $\mathrm{F}$ is the flow rate $\left(\mathrm{dm}^{3} \mathrm{~s}^{-1}\right)$; C is the concentration of reactant $\left(\mathrm{mol} \mathrm{dm}^{-3}\right) ; \mathrm{H}$ is the enthalpy of reaction $\left(\mathrm{kJ} \mathrm{mol}^{-1}\right)$; $\mathrm{k}$ is the rate constant $\left(\mathrm{s}^{-1}\right) ; \tau$ is the residence time of reacting solution $(\mathrm{s}) ; \mathrm{t}$ is time (s). By plotting the natural logarithm of power against time, a pseudo $1^{\text {st }}$ order rate constant for exponential growth under the conditions employed was obtained. This was validated against the value calculated from $\mathrm{OD}_{600}$ and dry weight measurements. Peak areas were calculated using MicroCal Origin 7.0 using the calculus function embedded in the software. Integration limits were chosen to omit the initial $10 \mathrm{~min}$ of data to minimize errors associated with the initiation of the experiment. The high limit was taken as being the very bottom of the down-curve of the glucose peak.

\section{Polysome profiling}

$50 \mathrm{~mL}$ of $2 \times$ CBS medium were inoculated with individual yeast colonies and cultured for up to $72 \mathrm{~h}$ in the presence or absence of $0.5 \mu \mathrm{g} / \mathrm{mL}$ doxycycline at $220 \mathrm{rpm}$ and $30^{\circ} \mathrm{C}$. These cultures were used to inoculate fresh $50 \mathrm{~mL} 2$ $\times$ CBS medium to a final $\mathrm{OD}_{600}$ of 0.1 and were cultured as above for $24 \mathrm{~h}$. $50 \mathrm{~mL} 2 \times$ CBS were inoculated to a final $\mathrm{OD}_{600}$ of 0.1 from these cultures and grown as stated above to a final $\mathrm{OD}_{600}$ of 1 . Cycloheximide was then added to the cultures to a final concentration of $10 \mu \mathrm{g} / \mathrm{mL}$ and incubated for $10 \mathrm{~min}$. Cells were recovered at 5,000 $\times$ $\mathrm{g}, 4^{\circ} \mathrm{C}, 5 \mathrm{~min}$, stored on ice and then suspended in $0.4 \mathrm{~mL}$ lysis buffer $(10 \mathrm{mM}$ Tris-HCl pH 7.4, $100 \mathrm{mM} \mathrm{NaCl}, 30$ $\mathrm{mM} \mathrm{MgCl}_{2}, 200 \mu \mathrm{g} / \mathrm{mL}$ heparin, $50 \mu \mathrm{g} / \mathrm{mL}$ cycloheximide, $1 \mathrm{mM} \mathrm{DTT}, 1 \mu \mathrm{l} / \mathrm{mL}$ RNase inhibitor and one EDTA-free protease inhibitor cocktail per $10 \mathrm{~mL}$ buffer) prepared in fresh DEPC-treated water with an equivalent volume of acid-washed glass beads. The cells were then disrupted in a Precellys 24 (Bertin Technology, France) at a speed of $6,500 \mathrm{rpm}$ for $10 \mathrm{~s}$. Samples were cooled on ice for $2 \mathrm{~min}$ followed by 2 additional rounds of disruption. The samples were clarified twice at $5,000 \times \mathrm{g}, 4^{\circ} \mathrm{C}, 5 \mathrm{~min}$ and $10,000 \times \mathrm{g}, 4^{\circ} \mathrm{C}, 20 \mathrm{~min}$ and the supernatant recovered. The RNA was subsequently quantified at $260 \mathrm{~nm}$ on a Nanodrop (Thermo Fisher Scientific, UK) and 5 - 10 $\mathrm{OD}_{600}$ units loaded on a freshly-prepared $10 \mathrm{~mL} 10-50 \%$ sucrose gradient. Gradients were ultracentrifuged at $37,000 \mathrm{rpm}, 4^{\circ} \mathrm{C}$ in a SW40 Beckman rotor for $2 \mathrm{~h} 40$ 
min. The $\mathrm{OD}_{254}$ profile of the gradients were recorded by chart recorder (Pharmacia LKB REC 102, GE Healthcare Life Sciences, UK) by passing the gradient (from the bottom of the tube to the top of the tube) through an AmershamPharmacia UV detector (GE Healthcare Life Sciences, UK) at a speed of $1.8 \mathrm{~mL} / \mathrm{min}$ with the simultaneous collection of $0.7 \mathrm{~mL}$ fractions. These fractions were stored at $-20^{\circ} \mathrm{C}$ for later analysis. For EDTA polysome disruption profiling, yeast cultures were prepared as above and the cells recovered in the absence of cycloheximide. Cells were resuspended in $0.4 \mathrm{~mL}$ lysis buffer lacking cyclohexamide, and disrupted and clarified as above. The RNA was quantified as previously stated and $10 \mathrm{OD}_{600}$ units were mixed with $50 \mathrm{mM}$ EDTA and loaded on top of freshlyprepared $10 \mathrm{~mL} 7.5-20 \%$ sucrose gradients. The gradients were then ultracentrifuged and processed as described above.

\section{Analysis of ribosomal RNA}

$50 \mathrm{~mL} 2 \times$ CBS medium were inoculated with individual yeast colonies transformed with the Fps1-HA 3 vector and cultured for up to $48 \mathrm{~h}$ in the presence or absence of various doxycycline concentrations at $220 \mathrm{rpm}$ and $30^{\circ} \mathrm{C}$. These cultures were used to inoculate fresh $50 \mathrm{~mL} 2 \times$ CBS medium containing various doxycycline concentrations to a final $\mathrm{OD}_{600}$ of 0.1 and were cultured as above to a final $\mathrm{OD}_{600}$ of $1-3$. Cells from $0.5 \mathrm{~mL}$ culture were collected by centrifugation at $1,000 \times \mathrm{g}, 4^{\circ} \mathrm{C}$ for $5 \mathrm{~min}$ and the supernatant discarded. The pellet was then processed and the RNA collected with an RNeasy Mini Kit (Qiagen) according to the standard enzymatic lysis protocol for yeast. The RNA was quantified and samples diluted to 150 $\mathrm{ng} / \mu \mathrm{L}$. The RNA samples were heated to $70^{\circ} \mathrm{C}$ for $3 \mathrm{~min}$ prior to loading $150 \mathrm{ng}$ samples in triplicate on an Agilent RNA 6000 Nanochip and running on an Agilent Bioanalyzer 2100 according to the manufacturer's instructions.

\section{Competing interests}

The authors declare that they have no competing interests.

\section{Authors' contributions}

$\mathrm{NiB}$ and $\mathrm{RD}$ were involved in all aspects of the experimental design, data collection, analysis and interpretation. LG participated in collecting the bioreactor data. $\mathrm{NaB}$ optimized and performed the microcalorimetry experiments. JW and SB performed the polysome profiling experiments. DP performed the binding assays. MO analyzed the microcalorimetry data. RB initiated the study, coordinated the data collection, analysis and interpretation, and drafted the manuscript. All authors contributed to the final version of the manuscript.

\section{Acknowledgements}

We gratefully acknowledge Drs Richard Kemp and Christer Larsson for their critical appraisal of our data, and Dr Martin Wilks for advice on the presentation of Figure 2. This work was supported by European Commis- sion contracts LSHG-CT-2004-50460I (E-MeP) and LSHG-CT-2006037793 (OptiCryst), and Technology Strategy Board grant TP/7/BIO/6/S/ M00I4B to RMB. The BBSRC supports bioreactors and a flow microcalorimeter in the RMB laboratory through an REI award. The work described here is the subject of UK patent application number 08/32253.2.

\section{References}

I. Schlyer S, Horuk R: I want a new drug: G-protein-coupled receptors in drug development. Drug Discov Today 2006, I I (I II 2):481-493.

2. Forstner M, Leder L, Mayr LM: Optimization of protein expression systems for modern drug discovery. Expert Rev Proteomics 2007, 4(I):67-78.

3. Bonander N, Hedfalk K, Larsson C, Mostad P, Chang C, Gustafsson $L$, Bill RM: Design of improved membrane protein production experiments: Quantitation of the host response. Protein Sci 2005, I4(7): 1729-1740.

4. Andre N, Cherouati N, Prual C, Steffan T, Zeder-Lutz G, Magnin T, Pattus F, Michel H, Wagner R, Reinhart C: Enhancing functional production of $\mathbf{G}$ protein-coupled receptors in Pichia pastoris to levels required for structural studies via a single expression screen. Protein Sci 2006, I5(5): I II5-II 26.

5. Islam RS, Tisi D, Levy MS, Lye GJ: Framework for the rapid optimization of soluble protein expression in Escherichia coli combining microscale experiments and statistical experimental design. Biotechnol Prog 2007, 23(4):785-793.

6. Martinez Molina D, Wetterholm A, Kohl A, McCarthy AA, Niegowski D, Ohlson E, Hammarberg T, Eshaghi S, Haeggstrom JZ, Nordlund P: Structural basis for synthesis of inflammatory mediators by human leukotriene C4 synthase. Nature 2007, 448(7| 53):6I3-6I6.

7. Wagner S, Baars L, Ytterberg AJ, Klussmeier A, Wagner CS, Nord O, Nygren PA, van Wijk KJ, de Gier JW: Consequences of membrane protein overexpression in Escherichia coli. Mol Cell Proteomics 2007, 6(9): I 527-1550.

8. Wagner S, Klepsch MM, Schlegel S, Appel A, Draheim R, Tarry M, Hogbom M, van Wijk KJ, Slotboom DJ, Persson JO, et al.: Tuning Escherichia coli for membrane protein overexpression. Proc Natl Acad Sci USA 2008.

9. Bill RM: Yeast - a panacea for the structure-function analysis of membrane proteins? Curr Genet 200I, 40(3): I57-I7I.

10. Hedfalk K, Bill RM, Mullins JG, Karlgren S, Filipsson C, Bergstrom J, Tamas MJ, Rydstrom J, Hohmann $S: A$ regulatory domain in the C-terminal extension of the yeast glycerol channel Fps Ip. J Biol Chem 2004, 279( I 5): | 4954- 14960.

I I. Tamas MJ, Karlgren S, Bill RM, Hedfalk K, Allegri L, Ferreira M, Thevelein JM, Rydstrom J, Mullins JG, Hohmann S: A short regulatory domain restricts glycerol transport through yeast FpsIp. J Biol Chem 2003, 278(8):6337-6345.

12. Wegierski T, Billy E, Nasr F, Filipowicz W: Bms I p, a G-domaincontaining protein, associates with $\mathrm{Rcllp}$ and is required for I 8S rRNA biogenesis in yeast. RNA 200 I, 7(9): I 254- I 267.

13. Wu PYJ, Ruhlmann C, Winston F, Schultz P: Molecular architecture of the S. cerevisiae SAGA complex. Mol Cell 2004, I5(2): 199-208.

14. Huisinga KL, Pugh BF: A genome-wide housekeeping role for TFIID and a highly regulated stress-related role for SAGA in Saccharomyces cerevisiae. Mol Cell 2004, I3(4):573-585.

15. Kornberg RD: Mediator and the mechanism of transcriptional activation. Trends Biochem Sci 2005, 30(5):235-239.

16. Thompson CM, Koleske AJ, Chao DM, Young RA: A Multisubunit Complex-Associated with the RNA Polymerase-II CTD and TATA-Binding Protein in Yeast. Cell I993, 73(7): I36I-I375.

17. Kidane A, Guan Y, Evans P, Kaderbhai M, Kemp R: Comparison of heat flux in wild-type and genetically-engineered chinese hamster ovary cells. J Thermal Anal 1997, 49:77|-783.

18. Barford JP: A general model for aerobic yeast growth: Batch growth. Biotechnol Bioeng 1990, 35(9):907-920.

19. Mutiu Al, Brandl CJ: RNA isolation from yeast using silica matrices. J Biomol Tech 2005, I 6(4):3 I6-3I7.

20. Young BP, Craven RA, Reid PJ, Willer M, Stirling CJ: Sec63p and Kar2 $p$ are required for the translocation of SRP-dependent precursors into the yeast endoplasmic reticulum in vivo. EMBO J 200I, 20(I-2):262-27I. 
21. Gelperin D, Horton L, Beckman J, Hensold J, Lemmon SK: Bms Ip, a novel GTP-binding protein, and the related Tsrlp are required for distinct steps of $40 \mathrm{~S}$ ribosome biogenesis in yeast. RNA 200I, 7(9): I268-I 283.

22. Karbstein K, Doudna JA: GTP-dependent formation of a ribonucleoprotein subcomplex required for ribosome biogenesis. J Mol Biol 2006, 356(2):432-443.

23. Volarevic S, Stewart MJ, Ledermann B, Zilberman F, Terracciano L, Montini E, Grompe M, Kozma SC, Thomas G: Proliferation, but not growth, blocked by conditional deletion of $40 \mathrm{~S}$ ribosomal protein S6. Science 2000, 288(5473):2045-2047.

24. Hoffmann F, Weber J, Rinas U: Metabolic adaptation of Escherichia coli during temperature-induced recombinant protein production: I. Readjustment of metabolic enzyme synthesis. Biotechnol Bioeng 2002, 80(3):3।3-319.

25. Hoffmann F, Rinas U: On-line estimation of the metabolic burden resulting from the synthesis of plasmid-encoded and heat-shock proteins by monitoring respiratory energy generation. Biotechnol Bioeng 200I, 76(4):333-340.

26. Henricsson C, de Jesus Ferreira MC, Hedfalk K, Elbing K, Larsson C, Bill RM, Norbeck J, Hohmann S, Gustafsson L: Engineering of a novel Saccharomyces cerevisiae wine strain with a respiratory phenotype at high external glucose concentrations. Appl Environ Microbiol 2005, 7 I (1 0):6I85-6I 92.

27. Gill NK, Appleton M, Lye GJ: Thermal profiling for parallel online monitoring of biomass growth in miniature stirred bioreactors. Biotechnol Lett 2008, 30(9): 157|-1575.

28. Rudra $D$, Warner JR: What better measure than ribosome synthesis? Genes Dev 2004, I 8(20):243I-2436.

29. Jorgensen P, Nishikawa JL, Breitkreutz BJ, Tyers M: Systematic identification of pathways that couple cell growth and division in yeast. Science 2002, 297(5580):395-400.

30. Smirnova JB, Selley JN, Sanchez-Cabo F, Carroll K, Eddy AA, McCarthy JE, Hubbard SJ, Pavitt GD, Grant CM, Ashe MP: Global gene expression profiling reveals widespread yet distinctive translational responses to different eukaryotic translation initiation factor 2B-targeting stress pathways. Mol Cell Biol 2005, 25(2I):9340-9349.

31. Fraser NJ: Expression and functional purification of a glycosylation deficient version of the human adenosine $2 \mathrm{a}$ receptor for structural studies. Protein Expr Purif 2006, 49(I): 129-137.

32. Velculescu VE, Zhang L, Zhou W, Vogelstein J, Basrai MA, Bassett DE Jr, Hieter P, Vogelstein B, Kinzler KW: Characterization of the yeast transcriptome. Cell 1997, 88(2):243-25I.

33. Poore V, Beezer A: Systematic errors in the measurement of heat by flow microcalorimetry. Thermochimica Acta 1983, 63:133-144.

Publish with Bio Med Central and every scientist can read your work free of charge

"BioMed Central will be the most significant development for disseminating the results of biomedical research in our lifetime. "

Sir Paul Nurse, Cancer Research UK

Your research papers will be:

- available free of charge to the entire biomedical community

- peer reviewed and published immediately upon acceptance

- cited in PubMed and archived on PubMed Central

- yours - you keep the copyright

Submit your manuscript here:

http://www.biomedcentral.com/info/publishing_adv.asp
BioMedcentral 